\title{
The effect of spatial rainfall variability on streamflow prediction for a south-eastern Australian catchment
}

\author{
$\underline{\text { F.F. Zhao }}^{\text {a }}$, L. Zhang ${ }^{\text {a }}$, F.H.S. Chiew ${ }^{\text {a }}$ and J. Vaze ${ }^{\text {a }}$ \\ ${ }^{a}$ Water for a Healthy Country Flagship, CSIRO Land and Water, Australian Capital Territory \\ Email: fangfang.zhao@csiro.au
}

\begin{abstract}
Spatial rainfall variability is considered an important factor affecting the accuracy of streamflow prediction. How does spatial rainfall variability affect catchment water balance? Can information of spatial rainfall variability improve streamflow prediction? This study was conducted to answer these questions. The modelling experiment was carried out using daily climate and streamflow data from a typical high yielding catchment in south-eastern Australia using the semi-distributed VIC (Variable Infiltration Capacity) model. Different spatial rainfall variability is generated and used as input into the VIC model to assess the sensitivity of streamflow to the spatial rainfall input.
\end{abstract}

The VIC model was first driven with $0.05^{\circ}$ gridded (distributed) daily rainfall series and calibrated against the observed daily streamflow data. The calibrated VIC model was used to simulate streamflow using both the distributed rainfall with different generated spatial rainfall variability and catchment-averaged rainfall. The effects of spatial rainfall variability on the streamflow prediction were assessed using a modified coefficient of efficiency and volumetric bias by comparing the simulated streamflow using the distributed rainfall and using the catchment-averaged rainfall. The differences in the streamflow volume and the daily streamflow distribution (daily flow duration curve) were assessed. The importance of accounting for spatial rainfall variability under different antecedent catchment condition (dry versus wet) was also assessed.

The modelling experiments show that for small spatial rainfall variability, modelling using the distributed rainfall and the catchment-averaged rainfall gives very similar results. For large spatial rainfall variability, not accounting for the spatial rainfall variability will lead to an underestimation of the total streamflow volume and the entire daily streamflow distribution. The modelling results also show that under wet antecedent catchment conditions and/or high rainfall events, the spatial runoff distribution is controlled mainly by the spatial rainfall falling on catchment, and under dry antecedent conditions, the spatial runoff across the catchment is controlled by the soil moisture distribution across the catchment.

Keywords: Spatial rainfall variability, streamflow prediction, hydrological mdoelling, Australia 
Zhao et al., The effect of spatial rainfall variability on streamflow predictions for Australian catchment

\section{INTRODUCTION}

Spatial rainfall variability is one of the main sources of uncertainty in streamflow simulation (Arnaud et al., 2011). An accurate assessment of the effect of spatial rainfall variability on streamflow is important for understanding the characteristics of catchment response (Singh, 1997). Studies investigating the effect of spatial rainfall variability on streamflow (Dawdy and Bergmann, 1969; Beven and Hornberger, 1982; Berndtsson and Niemcaynowicz, 1988; Krajewski et al. 1991; Obled et al., 1994; Arnaud et al., 2002; Segond et al., 2007; Arnaud et al., 2011) have concluded that proper consideration of spatial rainfall variability improves hydrological modeling particularly in the prediction of runoff volumes and peak flows and the timing of hydrographs. Most of these studies focus on the effect of spatial rainfall variability on modeling flood events.

Differences in simulated runoff using spatially distributed rainfall as opposed to spatially averaged rainfall were investigated by Obled et al. (1994), Arnaud et al. (2002), Segond et al. (2007) and Arnaud et al. (2011). They demonstrated the sensitivity of hydrological models to uncertainties in rainfall inputs and argued that distributed rather than lumped hydrological models are required in catchments with significant spatial rainfall variability. However, there is still no general conclusion about the relationship between spatial rainfall variability and streamflow response. The effect of spatial rainfall variability on streamflow may be catchment specific, depending on the particular catchment size, rainfall variability within the catchment and runoff generating mechanisms (Obled et al., 1994; Arnaud et al., 2002, Vaze et al., 2011b). It is important to understand how spatial rainfall variability interacts with catchment characteristics (e.g. catchment relief and vegetation cover) to produce observed streamflow regime. Due to the complexity of the problem, the effects of spatial rainfall variability are usually assessed indirectly, i.e. mainly using hydrological models (Obled $e t$ al., 1994; Segond et al., 2007).

This study is designed to address two research questions: (a) How would spatial rainfall variability affect catchment average water balance? (b) Can information of spatial rainfall variability improve daily streamflow prediction for Australian catchments? A large scale distributed hydrologic model (VIC) (Liang et al., 1994, 1996a, 1996b) is applied to a selected catchment in New South Wales, Australia to examine the sensitivity of the model to spatial rainfall variability in simulating daily streamflow.

\section{CATCHMENT DESCRIPTION AND DATA}

The Orara River at Bawden Bridge catchment was selected for this study. The catchment covers an area of $1790 \mathrm{~km}^{2}$ in the upper Clarence River (New South Wales) Australia. It is a typical high water yield catchment in south-eastern Australia with mean annual streamflow of $411 \mathrm{~mm}$ for the period of 1980-1985. The mean annual rainfall is $1358 \mathrm{~mm}$ for the same period and it ranges from $992 \mathrm{~mm}$ to $2242 \mathrm{~mm}$ across the catchment.

The daily streamflow data were obtained from the New South Wales Office of Water, and additional checks were carried out to ensure data quality for use in large-scale hydrological modeling (Vaze et al., 2011a). Daily rainfall, maximum and minimum temperatures over $0.05^{\circ}$ grids were obtained from the 'SILO Data Drill' of the Queensland Department of Natural Resources and Water (Jeffery et al., 2001; http:// http://www.longpaddock.qld.gov.au/silo/) to drive the VIC model.

\section{METHODOLOGY}

\subsection{Hydrologic model}

To investigate the effect of spatial rainfall variability on streamflow prediction, the Variable Infiltration Capacity (VIC) - 3L model is selected as the model has been widely applied in many catchments across the world. The detailed description of the VIC model can be found in Liang et al. (1994, 1996a, 1996b). Zhao et al. (2011) calibrated and tested the VIC model for Australian catchments and showed that the model can be well calibrated for most of the catchments. In this study, the model parameters are recalibrated for the Orara River catchment using the Genetic Algorithm (GA) global optimization method. Flow routing is also included in the VIC-3L model. Figure 1 shows the simulated and observed daily streamflow in the calibration period for the study catchment. The coefficient of efficiency $(E)$ (Nash and Sutcliffe, 1970) and bias (total prediction error divided by total observed streamflow) in the daily simulation are 0.89 and $4.5 \%$, indicating a good model calibration. 

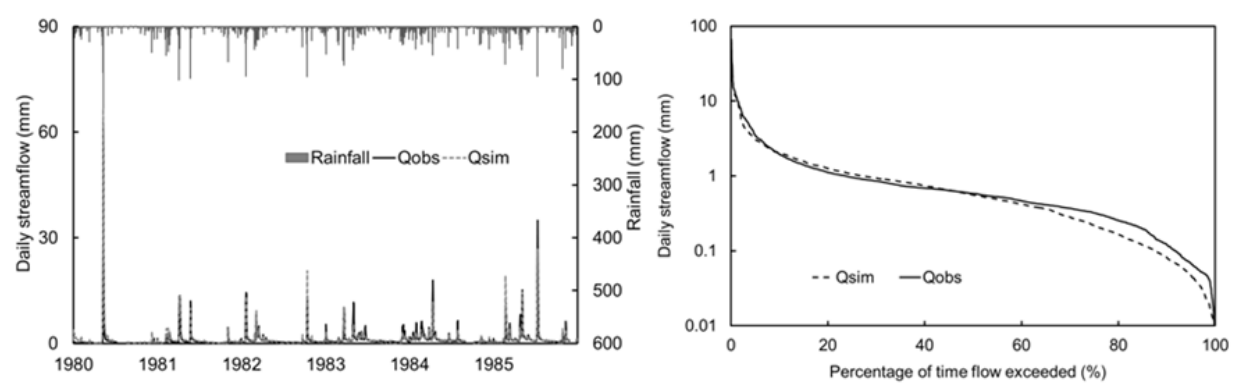

Figure 1. Comparison of observed and simulated daily streamflow and daily flow duration curves in the calibration period (1980-1985).

\subsection{Experiments with different levels of spatial rainfall variability}

To investigate the effects of spatial rainfall variability on streamflow prediction, a simple concept termed the "degree of spatial variability" (DSV) (Kling and Gupta, 2009) was used to generate rainfall scenarios from the gridded SILO rainfall with different degrees of spatial variability. For a given time scale (e.g. daily), rainfall data with different spatial variability can be generated as follows:

$$
P_{i, D S V}=\bar{P}+D S V *\left(P_{i, S I L O}-\bar{P}\right)
$$

where $P_{i, S I L O}$ represents the daily rainfall from SILO Data Drill at grid $i$ in $\mathrm{mm}$, and $\bar{P}$ is the catchment averaged rainfall in $\mathrm{mm}$. The gridded rainfall from SILO Data Drill represents rainfall data with spatial variability of unity (DSV $=1$ ). The catchment average rainfall is associated with zero spatial variability $(\mathrm{DSV}=0)$. By varying DSV between 0 and 1 using a step-size of 0.1 , we generated 11 rainfall time series with different degrees of spatial variability.

Once the spatially distributed rainfall time series were generated, the calibrated VIC-3L model was used to simulate daily streamflow. Then the effect of spatial rainfall variability on streamflow prediction was assessed by comparing streamflow simulated using spatial distributed rainfall data (DSV $\neq 0)$ and spatial averaged rainfall data (DSV=0). A modified coefficient of efficiency $\left(E_{0} v s n\right)$ was used to measure the performance of the model in simulating streamflow under different degrees of spatial rainfall variability in comparison to the simulated streamflow using spatially averaged rainfall:

$$
E_{0 v s k}=1-\frac{\sum\left(Q_{k}-Q_{0}\right)^{2}}{\sum\left(Q_{0}-\overline{Q_{0}}\right)^{2}} \quad(k=0.1,0.2, \ldots, 1.0)
$$

where $Q_{0}$ is the streamflow from simulation using spatial averaged rainfall (DSV $\left.=0\right), Q_{k}$ is the streamflow from simulations using spatial distributed rainfall with different spatial variability (DSV $=k$ ), and $\overline{Q_{0}}$ is the mean of $Q_{0}$.

\section{RESULTS AND DISCUSSION}

Figure 2 shows the model performance in terms of modified $E$ values and bias against degree of spatial variability (DSV) for the study catchment. As expected, the modified $E$ values decrease and bias increase with increasing spatial variability. When the spatial rainfall variability is low (i.e. DSV $\leq 0.3$ ), the use of spatially averaged rainfall yielded modified $E$ values closer to 1.0, indicating that the model performs well even without optimization. However, when the spatial rainfall variability is large (i.e. DSV $\geq 0.4$ ), the use of spatially averaged rainfall (i.e. neglecting spatial variability) yielded errors in the simulated daily streamflow. Similar results were also obtained by Arnaud et al. (2011). The method used in this study for assessing the effects of spatial rainfall variability on predicted streamflow assumes that (a) rainfall data from SILO Data Drill provide realistic quantitative and qualitative information about the spatial variability of rainfall; (b) the distributed VIC-3L model accurately takes into account rainfall distribution and simulates streamflow; and (c) the calibrated parameter values using gridded SILO rainfall data and measured streamflow fully represent the hydrologic characteristics of the study catchment. These assumptions enable us to assess the effects of spatial rainfall variability on simulated streamflow as the only difference in all the simulations is their degrees of rainfall variability. In other words, these simulations eliminate the effects of model structure errors and rainfall errors. 
Changes of the flow duration curves (FDCs) from different experiments can reflect the effects of spatial rainfall variability on percentile flow (i.e. peak flow) predictions, as a flow duration curve (FDC) is one of the informative ways of displaying the complete range of streamflow from a catchment (Smakhtin, 2001). Figure 3 shows the daily flow duration curves (FDCs) from different experiments in the period of 19801985. Compared with the FDC of the experiment using spatial averaged rainfall (DSV=0), the use of spatial distributed rainfall $(\mathrm{DSV} \neq 0$ ) increased the daily streamflow for most percentiles. However, the changes in FDCs are small.

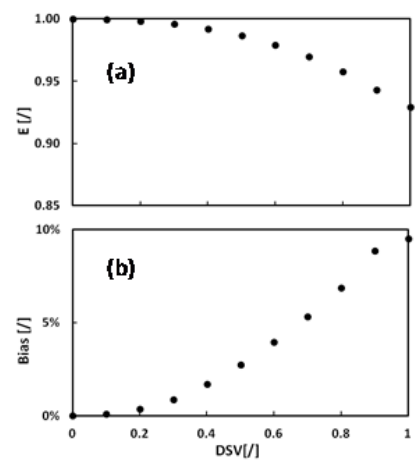

Figure 2. Impact of spatial rainfall variability on model performance (modified $E$ values and bias).

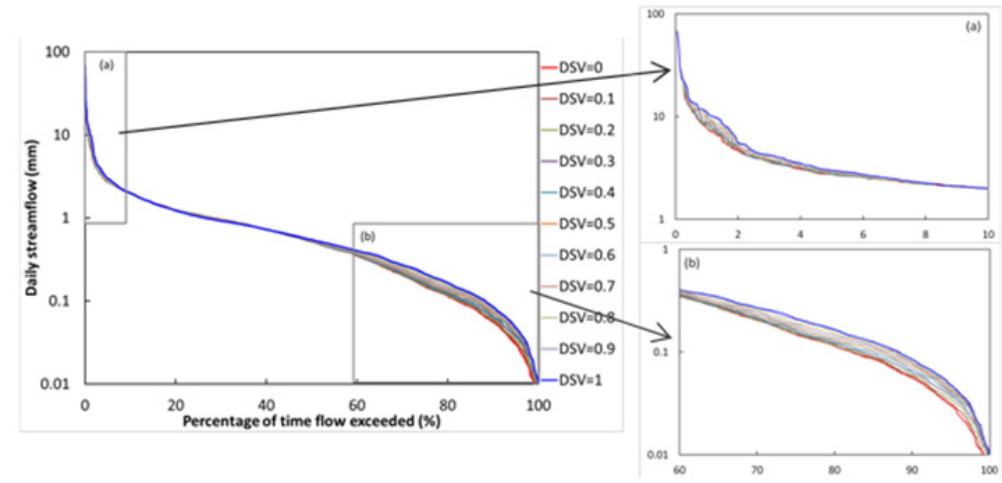

Figure 3. Effect of rainfall spatial variability on daily flow duration curves.

The effects of spatial rainfall variability on streamflow response are likely to vary depending on antecedent conditions, e.g., dry and wet conditions (Singh, 1997). Shah et al. (1996) observed higher errors in runoff prediction under dry conditions than under wet conditions. To investigate the effect of spatial rainfall variability on streamflow prediction under different climatic conditions, the spatial maps of four water balance variables (rainfall, runoff, evapotranspiration and soil moisture) from different experiments on a wet day (20/02/1985) and a dry day (13/08/1985) are plotted in Figure 4 and Figure 5.

On the wet day, the spatial distribution of runoff is very similar to that of the rainfall, indicating that runoff was dominated by quick surface runoff generation. It has been suggested that in energy-limited conditions, i.e. wet conditions, rainfall variability is largely translated into variability in runoff (Koster and Suarez, 1999; Potter and Zhang, 2007). The results of Figure 4 appear to be consistent with the hypothesis. When spatially averaged rainfall was used, runoff variability was significantly reduced as expected. The spatial variability of runoff indicates existence of variability in soil and vegetation characteristics in the catchment. The use of spatially averaged rainfall affected the distribution of soil moisture, but did not affect distribution of evapotranspiration. The variability of soil moisture decreased when spatially averaged rainfall was used, while the soil wetness increased. The catchment averaged soil moisture is $243 \mathrm{~mm}$ when DSV $=1$, but it is $261 \mathrm{~mm}$ when DSV $=0$. The results support the findings of Sivapalan and Woods (1995) in that ignoring rainfall spatial variability can lead to higher soil moisture storage. The study of Sivapalan and Woods (1995) was focused on sub-grid variability of rainfall on water balance fluxes. The effect of spatial rainfall variability investigated in this study reflects accumulated effect of sub-grid variability without explicitly addressing the issue of sub-grid variability. When using different levels of spatial rainfall variability (Figure 4 (b-f)), the runoff showed stronger sensitivity to rainfall and soil moisture than ET.

On the dry day, the spatial distribution of runoff is very similar to that of the soil moisture, indicating that runoff was dominated by baseflow. This is different from that observed on the wet day when runoff was dominated by the rainfall distribution. However, the spatial distribution of evapotranspiration is similar to that of the rainfall. The effect of rainfall variability on streamflow depends on climatic conditions and in water-limited conditions, as shown in Figure 5, rainfall variability largely results in variability in evapotranspiration (Koster and Suarez, 1999; Potter and Zhang, 2007). This would imply that the runoff variability in water-limited conditions is relatively insensitive to rainfall variability. Similar to that of the wet day response, runoff variability was reduced when spatially averaged rainfall was used. Evapotranspiration also responded to the change in rainfall variability. Soil moisture distribution did not change very much when averaged rainfall was used, but the soil wetness increased. The change of the soil moisture on dry day is similar to that of the wet day shown in Figure 4. Different levels of spatial rainfall variability resulted in little change in runoff and soil moisture. This may be due to the fact this is a dry day with average daily rainfall of $0.07 \mathrm{~mm}$. 
(a)

\begin{tabular}{|c|c|}
\hline & Runoff (mm) \\
\hline
\end{tabular}

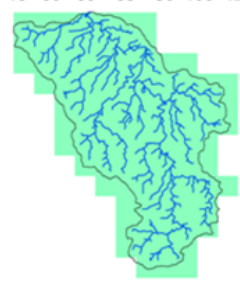

(b)

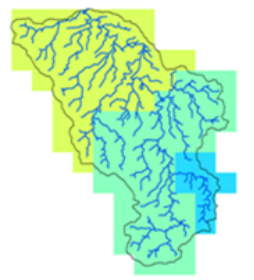

(c)

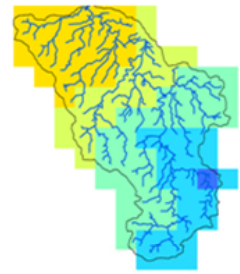

(d)

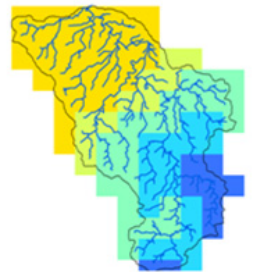

(e)

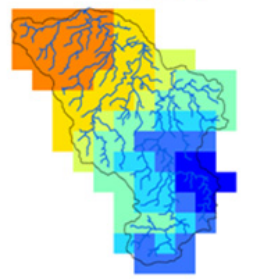

(f)
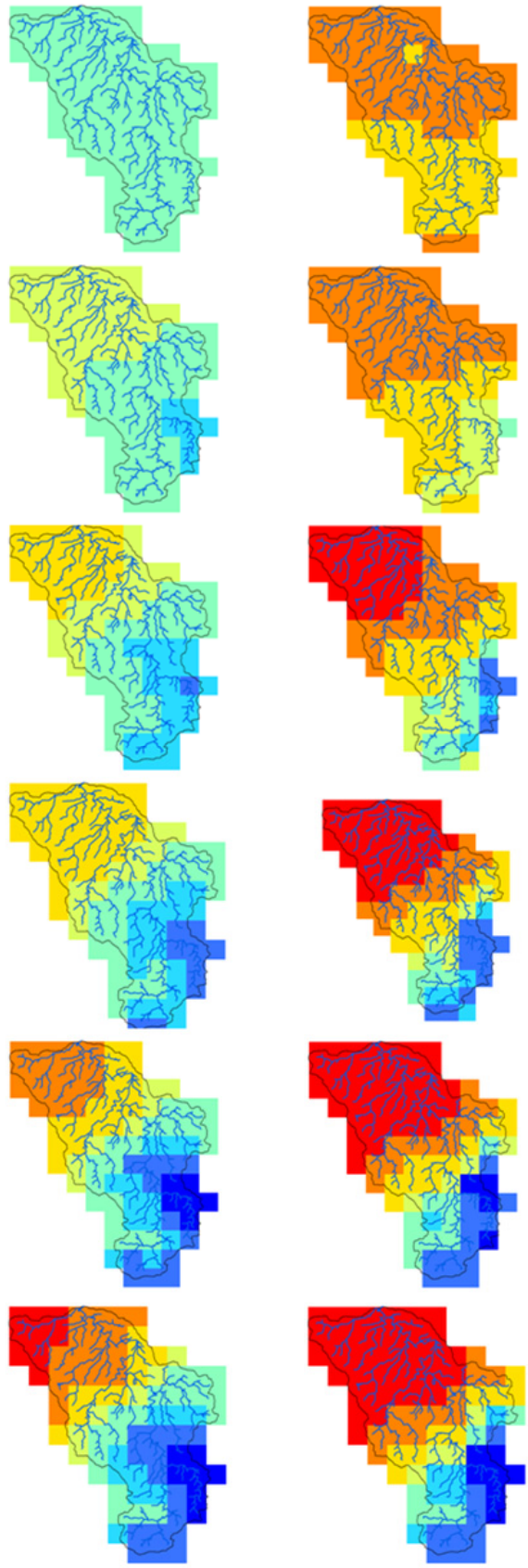

$\mathrm{ET}(\mathrm{mm})$

Soil Moisture (mm)

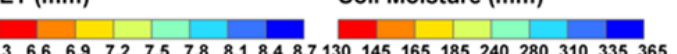
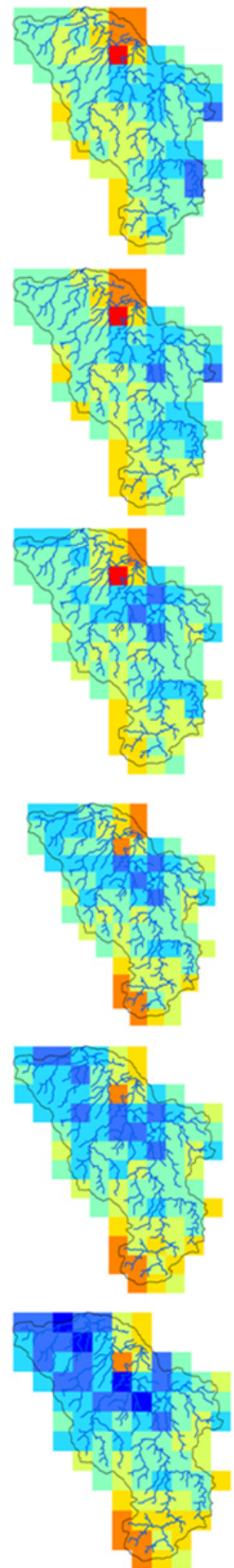
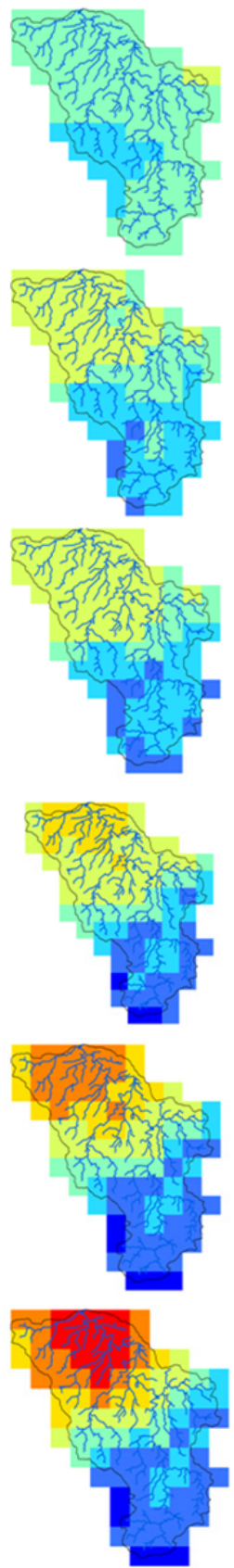

Figure 4. Spatial maps of rainfall, runoff, evapotranspiration and soil moisture from the different simulations on a wet day $(20 / 02 / 1985)$ based on (a) catchment-averaged rainfall (DSV $=0),(b-f)$ rainfall with different levels of spatial variability (DSV $=0.2,0.4,0.6,0.8$, and 1.0 ).

\section{CONCLUSIONS}

This study investigated the effect of spatial rainfall variability on streamflow prediction in the Orara River catchment in NSW Australia using the VIC-3L model. The effect of spatial rainfall variability on streamflow was assessed by running the VIC-3L model with rainfall time series generated by varying the spatial rainfall variance. The results show that neglecting spatial rainfall variability will impact the streamflow simulation in large catchments. Percentile daily flows increase with spatial rainfall variability. The study also showed that the spatial distribution of runoff is controlled by the spatial rainfall variability on a wet day and by the soil moisture distribution on a dry day. The preliminary results from this study suggest that more accurate information of rainfall distribution in a catchment can help to improve daily water balance modeling. 


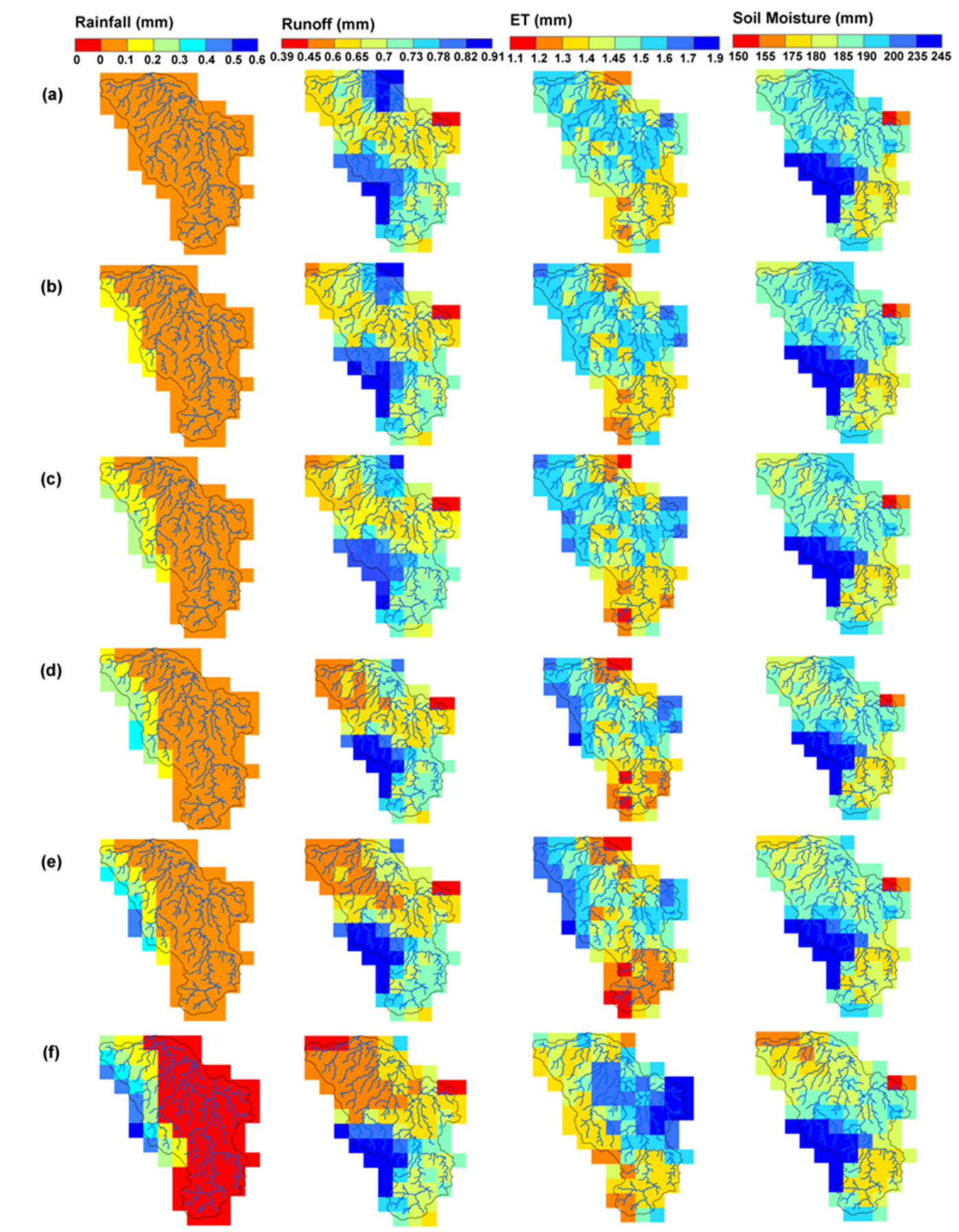

Figure 5. Spatial maps of rainfall, runoff, evapotranspiration and soil moisture from the different simulations on a dry day (13/08/1985) based on (a) catchment-averaged rainfall (DSV=0), (b - f) rainfall with different levels of spatial variability $(\mathrm{DSV}=0.2,0.4,0.6,0.8$, and 1.0$)$.

\section{ACKNOWLEDGMENTS}

This study was supported by the CSIRO OCE Postdoctoral Fellowship Program and Water for a Healthy Country National Research Flagship. The authors would like to thank Cuan Petheram and two anonymous reviewers for the valuable comments and suggestions.

\section{REFERENCES}

Arnaud, P., Bouvier, C., Cisneros, L., Dominguez, R. (2002). Influence of rainfall spatial variability on flood prediction. Journal of Hydrology, 260, 216-230. 
Zhao et al., The effect of spatial rainfall variability on streamflow predictions for Australian catchment

Arnaud, P., Lavabre, J., Fouchier, C., Diss, S., and Javelle, P. (2011). Sensitivity of hydrological models to uncertainty in rainfall input. Hydrological Sciences Journal, 56:3, 397-410

Berndtsson, R., and Niemczynowicz, J. (1988). Spatial and temporal scales in rainfall analysis. Some aspects and future perspective. Journal of Hydrology, 100, 293-313.

Beven, K.J., and Hornberger, G.M. (1982). Assessing the effect of spatial pattern of precipitation in modeling stream-flow hydrographs. Water Resources Bulletin, 18(5), 823-829.

Dawdy, D.R., and Bergman, J.M. (1969). Effect of rainfall variability on streamflow simulation. Water Resources Research, 5, 958-969.

Jeffrey, S.J., Carter, J.O., Moodie, K.M., and Beswick, A.R. (2001). Using spatial interpolation to construct a comprehensive archive of Australian climate data. Environmental Modelling and Software, 16/4, 309-330.

Kling, H., and Gupta, H. (2009). On the development of regionalization relationships for lumped watershed models: The impact of ignoring sub-basin scale variability. Journal of Hydrology, 373, 337-351.

Koster, R.D., and Suarez, M.J. (1999). A simple framework for examining the interannual variability of Land surface moisture fluxes. Journal of Climate, 12, 1911-1917.

Krajewski, F.W., Lakshmi, V., Georgakakos, K.P., and Jain, S. (1991). A Monte Carlo study of rainfall sampling effect on a distributed catchment model. Water Resources Research, 27(1), 119-128.

Liang, X., Lettenmaier, D.P., and Wood, E.F. (1996a). One-dimensional Statistical Dynamic Representation of Subgrid Spatial Variability of Precipitation in the Two-Layer Variable Infiltration Capacity Model, Journal of Geophysical Research, 101(D16), 21,403-21,422.

Liang, X., Lettenmaier, D.P., Wood, E.F., and Burges, S.J. (1994). A simple hydrologically based model of land surface water and energy fluxes for GSMs, Journal of Geophysical Research, 99(D7), 14,41514,428

Liang, X., Wood, E.F., and Lettenmaier, D.P. (1996b). Surface soil moisture parameterization of the VIC-2L model: Evaluation and modifications, Global and Planetary Change, 13, 195-206.

Nash, J.E., and Sutcliffe, J.V. (1970). River flow forecasting through conceptual models, I, A discussion of principles. Journal of Hydrology, 10: 282-290.

Obled, Ch., Wendling, J., and Beven, K. (1994). The sensitivity of hydrological models to spatial rainfall patterns: an evaluation using observed data. Journal of Hydrology, 159, 305-333.

Potter, N.J., and Zhang, L. (2007). Water balance variability at the interstorm timescale. Water Resources Research, 43, W05405, doi:10.1029/2006WR005276.

Segond, M.-L., Wheater, H.S., and Onof, C. (1997). The significance of spatial rainfall representation for flood runoff estimation: A numerical evaluation based on the Lee catchment, UK. Journal of Hydrology, $347,116-131$.

Shah, S., O'Connel, P., Hosking, J. (1996). Modelling the effects of spatial variability in rainfall on catchment response. 2. Experiments with distributed and lumped models. Journal of Hydrology, 175, 89111.

Singh, V.P. (1997). Effect of spatial and temporal variability in rainfall and watershed characteristics on stream flow hydrograph. Hydrological Processes, 11, 1649-1669.

Sivapalan, M., and Woods, R.A. (1995). Evaluation of the effects of general circulation models' subgrid variability and patchiness of rainfall and soil moisture on land surface water balance fluxes. Hydrological Processes, 9, 697-717.

Smakhtin, V.Y. (2001). Low flow hydrology: a review. Journal of Hydrology, 240, 147-186.

Vaze, J., Chiew, F.H.S., Perraud, J.-M., Viney, N., Post, D.A., Teng, J., Wang, B., Lerat, J., and Goswami, M. (2011a). Rainfall-runoff modelling across southeast Australia: datasets, models and results. Australian Journal of Water Resources, 14(2), 101-116.

Vaze, J., Post, D.A., Chiew, F.H.S., Perraud, J.-M., Viney, N., Teng, J. (2011b). Effect of Input Rainfall Data and Spatial Modelling on Rainfall Runoff Model Performance and optimised parameter values, Journal of Hydrometeorology, doi: 10.1175/2011JHM1340.1.

Zhao, F.F., Chiew, F.H.S., Zhang, L., Vaze, J., Perraud, J.-M., and Li, M. (2011). Application of a macroscale hydrologic model to estimate streamflow across southeast Australia. Journal of Hydrometeorology (in review). 